\title{
An Incidental Finding of a Radiopaque Pill following Cervical Spinal Surgery in a Parkinson's Disease Patient
}

\author{
Bon Sub Gu${ }^{1}$, Soo-Jung $\mathrm{Choi}^{2}$, Byoungwoo Yoo ${ }^{3}$, Koon Hee $\mathrm{Han}^{4}$, Jong Kyu Park ${ }^{4}$, \\ Young-Seok Lee ${ }^{1}$, Jin Hoon Park ${ }^{1}$
}

Departments of ${ }^{1}$ Neurological Surgery, ${ }^{2}$ Radiology, ${ }^{3}$ Anesthesiology, ${ }^{4}$ Internal Medicine, Gangneung Asan Hospital, University of Ulsan College of Medicine, Gangwon-do, Korea

There are previous reports of the identification of radiopaque medications on abdominal X-rays or computed tomography (CT). We describe an interesting case of the incidental identification of a radiopaque medication on cervical spinal CT following cervical spinal surgery. A sixty seven-year-old male patient with Parkinson's disease (PD) visited our emergency center with a C5-6 dislocation and fracture. Surgery was performed with open reduction and pedicle screw fixation through the posterior approach. No abnormal events occurred during the perioperative period. However, a radiopaque incidental foreign body in front of the C6 vertebrae was found on a cervical spinal CT and X-rays that were performed as routine examinations on postoperative day 3. After 6 hours, we performed gastrofibroscopy (GFS) but were unable to find anything. Therefore, we checked all of his medications related to the neck and check X-ray again. One enteric-coated pill he had taken exhibited strong radiodensity. Although our patient underwent an unnecessary GFS, every spinal surgeon should keep in mind that radiopaque pills can appear similar to spinal instruments on X-ray and CT. In addition, we should also know the associated dysphagia is a possible cause of the delayed passage of medicine in PD with or without cervical osteophytes.

Key Words: Foreign bodies $\cdot$ Dislocations $\cdot$ Gastroscopy $\cdot$ X-Rays $\cdot$ Parkinson's disease

\section{INTRODUCTION}

There are previous reports of the identification of such radiopaque medications on abdominal X-rays and computed tomography $(\mathrm{CT})^{4,7)}$. However, there are no reports of such medications being identified on cervical spinal CT.

Parkinson's disease (PD) is related to dysphagia, which can impair bolus transport. Additionally, osteophytes have been reported to aggravate the dysphagia ${ }^{1,3,14,17)}$.

Here, we describe an interesting case in which radiopaque medication was incidentally found on a cervical spinal CT following cervical spinal surgery in a PD patient.

\footnotetext{
- Received: June 1, 2015 • Revised: July 24, 2015

- Accepted: July 28, 2015

Corresponding Author: Jin Hoon Park, MD, PhD

Department of Neurological Surgery, Gangneung Asan Hospital, University of Ulsan College of Medicine, 38, Bangdong-gil, Sacheon-myeon,

Gangneung-si, Gangwon-do 25440, Korea

Tel: +82-33-610-3260, Fax: +82-33-610-4960

E-mail: grandblue@gnah.co.kr

$\otimes$ This is an Open Access article distributed under the terms of the Creative

Commons Attribution Non-Commercial License (http://creativecommons.org/ licenses/by-nc/3.0/) which permits unrestricted non-commercial use, distribution, and reproduction in any medium, provided the original work is properly cited.
}

\section{CASE REPORT}

A sixty seven-year-old male patient visited at our emergency center with neck pain that developed after a fall. His physical and neurological examinations were normal on admission. $\mathrm{He}$ had taken several medications due to his PD. A lateral cervical X-ray image revealed subluxation at the C5-6 level and a cervical osteophyte at the anterior-inferior corner of C5 vertebrae. Cervical CT revealed a left-side C5 inferior articular process fracture and displacement. There was no cervical spinal cord compression on magnetic resonance imaging. We assessed the cervical facet fracture and subluxation and planned an elective surgery for the next day.

The surgery was performed with open reduction and pedicle screw fixation through the posterior approach. No abnormal events occurred during the perioperative period. However, a foreign body was incidentally found on a cervical spinal $\mathrm{CT}$ that was performed as a routine examination on postoperative day 3. The foreign body was located in front of the C6 vertebral body an appeared as a metal cervical interbody cage. The foreign body seemed to be located inside the esophagus and its Hounsfield unit value as 3,000. A cervical X-ray performed after three hours also showed the same foreign body 


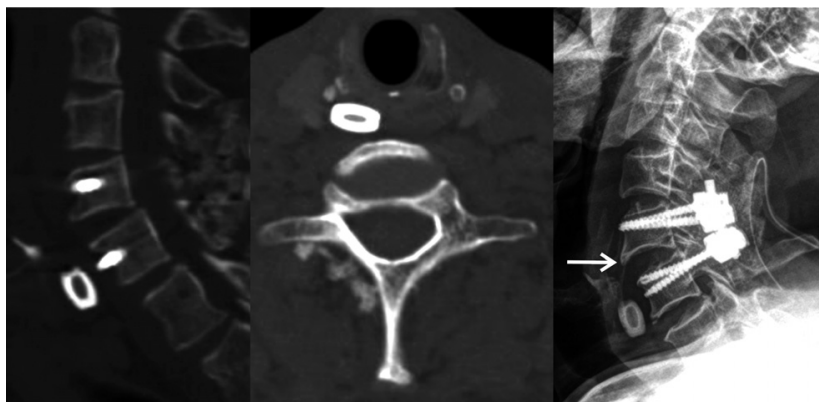

Fig. 1. Cenvical CT and X-ray showing the foreign body that looked like a cage in front of the C6 vertebrae. Osteophyte can be seen at the anterior-inferior corner of C5 vertebrae (arrow).

in front of the C6 vertebrae (Fig. 1). We believed that it was a metal foreign body that the patient had carelessly eaten. Therefore, we planned to remove it with gastrofiberscopy (GFS). During the GFS that was performed three hours after the X-ray, we were unable to find anything in the esophagus. After removing the GFS, we again checked cervical spine and abdomen X-rays and found that there was no abnormal foreign body. Thus, we checked X-ray of the neck with the skin attached in relation to all of the patient's medications. We find that a Sinemet $\mathrm{CR}^{\circledR}$ (composite of levodopa and carbidopa) pill attached to the neck appeared as a radiopaque density and looked like a cage (Fig. 2).

\section{DISCUSSION}

One study reported many medication that could potentially appear as radiopaque densities on X-ray ${ }^{4,7}$. The mnemonic "CHIPES" has been used to describe the common radiopaque medications including chloral hydrate, heavy metals, iron, phenothiazines, and slow-release drugs ${ }^{4-6,11,15)}$ (Table 1). Of the medications studied, potassium chloride was the most radiopaque, and prednisone was the least radiopaque. As a group, minerals were the most radiopaque of all medications studied ${ }^{4)}$. Another study reported all of the medicines that can potentially be observed as radiopaque on X-ray ${ }^{2}$.

Our patient had also taken an enteric-coated slow release tablet. If we had the information that slow-release medications could exhibit high radiodensities, our patient would not have been subjected to an unnecessary GFS. Because an immediate postoperative X-ray did not reveal any abnormal findings and because we used the posterior approach, we did not believe that the object could be a surgical foreign body despite its appearance as an interbody cage ${ }^{12,13)}$. If we had encountered a similar situation following an anterior cervical operation, we would have been much more embarrassed ${ }^{16}$. Thus, the most

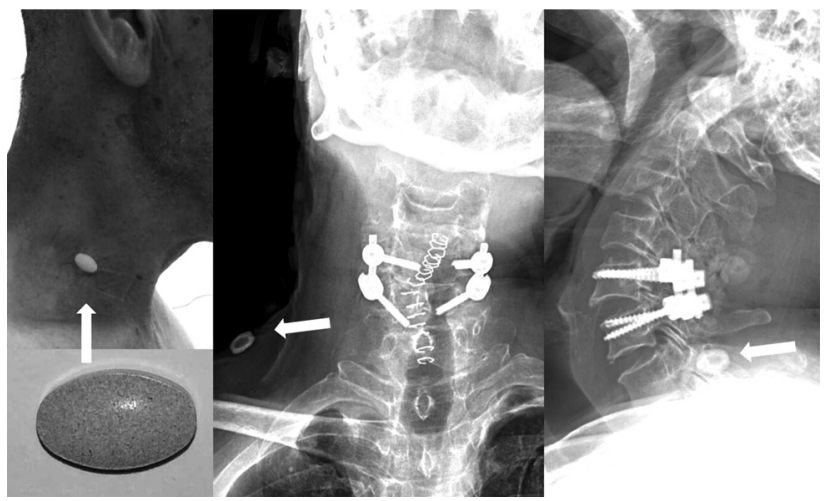

Fig. 2. The radiopaque pill attached to the neck exhibited a cagelike appearance on the X-rays (arrows).

Table 1. Agents those are potentially radiopaque on plain X-ray

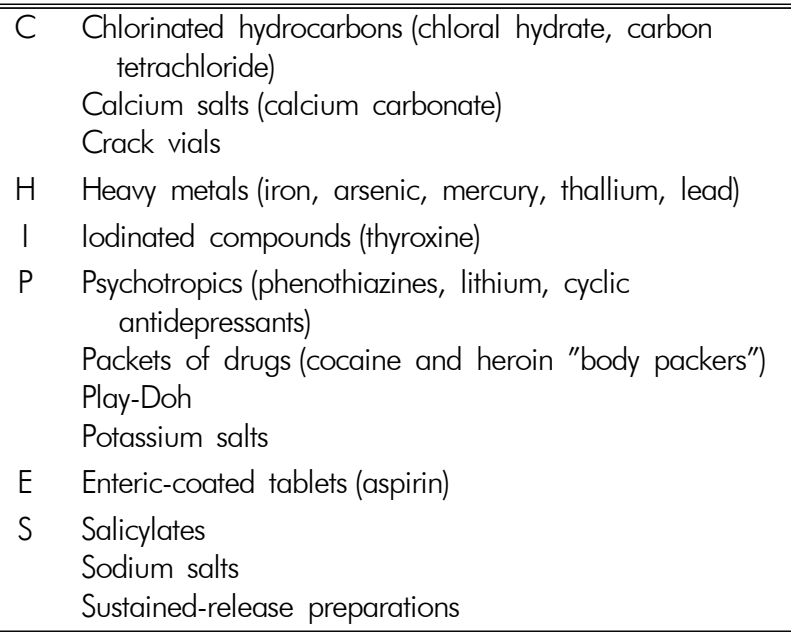

plausible scenario is that the patient had carelessly eaten a metal foreign body. After discussing this case with a gastroscopist and a radiologist, we determined to remove the foreign body. If we had checked the X-ray immediately prior to the GFS and suspected the foreign body was a radiopaque medicine, we would not have performed the useless procedure on the patient.

Dysphagia occurs in 10-80\% of PD patients, and survey studies have suggested that approximately $50 \%$ of PD patients report symptomatic dysphagia ${ }^{8}$. Dysphagia in PD is exhibited as the incomplete opening of the upper esophageal sphincter, and all stages of swallowing, the preoral, oral, lingual, pharyngeal, and esophageal stages, may be affected. The most typical symptom is a prolongation of the swallowing reaction time that includes decreased mastication and lip sealing, delayed bolus transit, disordered and fragmented transfer and peristalsis, delayed swallowing reflexes, and deficits in laryngeal movement $^{3,8,14,17)}$. Additionally, cervical osteophytes can aggravate dysphagia in $\mathrm{PD}^{9,10)}$. Regarding treatments of dysphagia in 
PD, rehabilitation (swallowing training), cricopharyngeal sphin tectomy, and pharmacologic therapies have been reported ${ }^{1,3,14,17}$. In our patient, we believe that the coexistence of PD and an osteophyte might have contributed the delayed passage of the radiopaque pill.

A previous study reported that the levodopa-carbidopa medicine is radiolucent. However, it also described that different medicines and even the same medicines from different manufacturers exhibit different levels of radiopacity ${ }^{2}$. Thus, the pill in our patient was radiopaque despite the previous descriptions of this composite medicine of levodopa and carbidopa as radiolucent.

\section{CONCLUSION}

We presented a case involving a retained radiopaque pill in the esophagus following cervical spinal surgery. In Parkinson's disease with or without cervical osteophytes, the associated dysphagia is a possible cause of the delayed passage of medicine. Additionally, spinal surgeons should keep in mind that radiopaque pills can appear similar to spinal instruments on X-ray and CT.

\section{REFERENCES}

1. Baijens LW, Speyer R: Effects of therapy for dysphagia in Parkinson's disease: systematic review. Dysphagia 24:91-102, 2009

2. Chan YC, Lau FL, Chan JCS, Hon TWY: A study of drug radiopacity by plain radiography. Hong Kong J Emerg Med 11:205210, 2004

3. Edwards LL, Pfeiffer RF, Quigley EM, Hofman R, Balluff M: Gastrointestinal symptoms in Parkinson's disease. Mov Disord 6:151-156, 1991
4. Florez MV, Evans JM, Daly TR: The radiodensity of medications seen on x-ray films. Mayo Clin Proc 73:516-519, 1998

5. Handy CA: Radiopacity of oral nonliquid medications. Radiology 98:525-533, 1971

6. Hinkel CL: The significance of opaque medications in the gastrointestinal tract, with special reference to enteric coated pills. Am J Roentgenol Radium Ther 65:575-581, 1951

7. Judge BS, Hoyle JD Jr.: Incidental discovery of radiopaque pills on abdominal CT in a patient with abdominal pain. Clin Toxicol (Phila) 46:574-575, 2008

8. Kim JS, Sung HY: Gastrointestinal autonomic dysfunction in patients with Parkinson's disease. J Mov Disord 8:76-82, 2015

9. Ladenheim SE, Marlowe FI: Dysphagia secondary to cervical osteophytes. Am J Otolaryngol 20:184-189, 1999

10. Lee SH, Bae SO, Paik NJ: Aggravated dysphagia caused by cervical osteophyte in a patient with Parkinson disease. Am J Phys Med Rehabil 93:e19, 2014

11. O'Brien RP, McGeehan PA, Helmeczi AW, Dula DJ: Detectability of drug tablets and capsules by plain radiography. Am J Emerg Med 4:302-312, 1986

12. Park JH, Roh SW, Rhim SC: A single-stage posterior approach with open reduction and pedicle screw fixation in subaxial cervical facet dislocations. J Neurosurg Spine 23:35-41, 2015

13. Park JH, Jeon SR, Roh SW, Kim JH, Rhim SC: The safety and accuracy of freehand pedicle screw placement in the subaxial cervical spine: a series of 45 consecutive patients. Spine (Phila Pa 1976) 39:280-285, 2014

14. Pfeiffer RF: Gastrointestinal dysfunction in Parkinson's disease. Parkinsonism Relat Disord 17:10-15, 2011

15. Savitt DL, Hawkins HH, Roberts JR: The radiopacity of ingested medications. Ann Emerg Med 16:331-339, 1987

16. Shin JS, Oh SH, Cho PG: Surgical outcome of a zero-profile device comparing with stand-alone cage and anterior cervical plate with iliac bone graft in the anterior cervical discectomy and fusion. Korean J Spine 11:169-177, 2014

17. Siddiqui MF, Rast S, Lynn MJ, Auchus AP, Pfeiffer RF: Autonomic dysfunction in Parkinson's disease: a comprehensive symptom survey. Parkinsonism Relat Disord 8:277-284, 2002 